\title{
PENERAPAN SISTEM STOP SIGN PADA PERTIGAAN JALAN BERBASIS SENSOR PHOTOELECTRIC STUDI KASUS PADA PT.CHEVRON PACIFIC INDONESIA
}

\author{
Kadirun, Hasanuddin, dan Aryanto \\ Fakultas Ilmu Komputer Universitas Muhammadiyah Riau
}

\begin{abstract}
Abstrak-Kendaraan merupakan sarana transportasi yang sangat dibutuhkan masyarakat. Dimana dengan adanya sarana transportasi dapat memudahkan masyarakat untuk mencapai lokasi yang dituju dengan waktu yang singkat. Fungsi kendaraan sebagai sarana transportasi kadang disalah gunakan oleh sebagian orang, seperti mengendarai kendaraan tidak berhenti pada tanda stop dipertigaan jalan. Seperti pertigaan jalan yang ada pada PT. Chevron Pasific Indonesia. Hal ini tentu melanggar peraturan yang ada pada PT. Chevron Pasific Indonesia. Untuk itulah penulis mencoba membuat sistem stop sign kendaraan, dimana sistem ini diharapkan dapat membantu instansi securitysebagai petugas lalu lintasyang ada pada PT. Chevron Pasific Indonesia. PLC Omron CPIE-E10DR-Adigunakan untuk pemproses program yang di set dari komputer. SensorPhotoelectric Optex fa VD-300digunakan untuk mendektesi kendaraan yang melewati pertigaan jalan.Kamera axis Q1614 digunakan untuk merekam pelanggaran yang terjadi di pertigaaan jalan.Hasil penelitian menunujukkan alat yang dibuat dapat berfungsi dengan baik dan dapat dikembangkan untuk skala yang lebih besar.
\end{abstract}

Kata Kunci : PLC Omron CP1E-E10DRA,Sensor Photoelectric Optex fa VD300,Kamera axis Q1614.

\section{PENDAHULUAN}

Jalur lalu lintas yang ada di PT. Chevron Pacific Indonesia merupakan percontohan yang sangat tertib dalam mematuhi rambu-rambu lalu lintas. Biasanya pada saat jam-jam lalu lintas padat, yaitu pagi hari disaat jam masuk kerja dan sore hari saat jam pulang kerja pihak security bagian patrol melakukan pengawasan langsung dan berjaga dipersimpangan atau pertigaan jalan tempat peneliti melakukan penelitian untuk mengatur lalu lintas jalan. Namun, pihak security tidak dapat setiap saat berjaga dan mengawasi setiap persimpangan atau pertigaan jalan yang ada di lingkungan PT. Chevron Pasific Indonesia.

\section{LANDASAN TEORI}

\section{a. Sensor Photoelectric}

Sensor photoelectric adalah alat yang digunakan untuk mendeteksi keberadaan suatu objek yang biasanya berbentuk padat. Alat ini menggunakan energi cahaya yang berasal dari energi listrik sebagai penginderanya.

Berdasarkan prinsip kerjanya, secara umum alat ini dibagi ke dalam dua jenis. Jenis yang pertama ialah jenis refleksi, pada jenis ini alat pengirim cahaya (transmitter) dan penerima cahaya (receiver) berada pada satu tempat. Apabila ada benda pada posisi yang dideteksi maka cahaya yang di kirimkan oleh sensor ini akan dipantulkan kembali ke arah sensor itu dengan sudut yang berbeda tetapi masih dalam sumbu yang sama. Untuk lebih jelasnya dapat di lihat pada gambar 2.1 


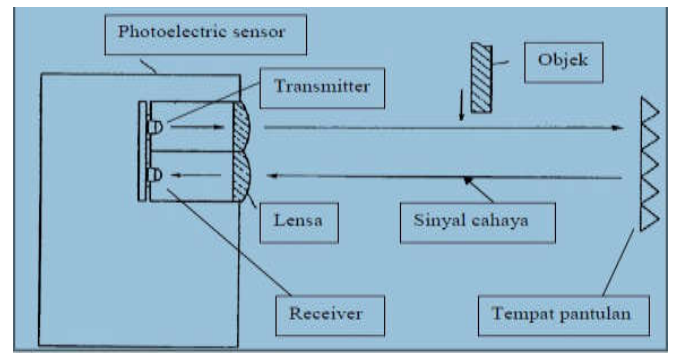

Gambar 1 Prinsip Kerja Sensor Photoelectric Tipe Refleksi.

Jenis yang ke dua ialah penetrasi, pada jenis ini transmitter dan receiver tidak berada pada suatu tempat. Pada saat tidak ada benda pada posisi yang dideteksi maka cahaya yang dikrimkan akan diterima oleh receiver, demikian sebaliknya jika benda ada pada posisi yang dideteksi maka cahaya yang di

kirimkan tidak sampai kepada receiver. Untuk lebih jelasnya dapat dilihat pada Gambar 2.2

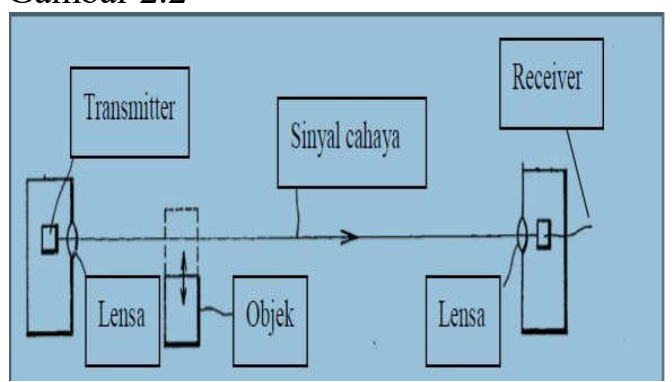

Gambar 2 Prinsip Kerja Sensor Photoelectric Tipe Penetrasi

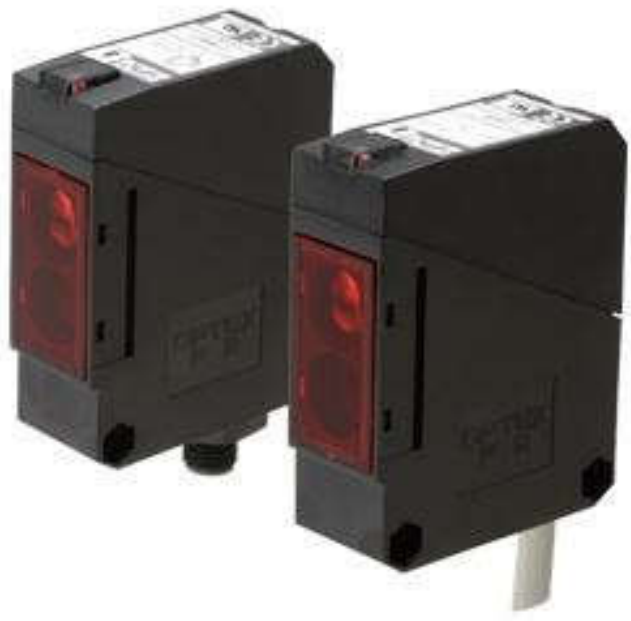

( Sumber: http://www.optex-fa.com/ ) Gambar 3 Sensor Photoelectric Optex fa VD-300.

\section{b. Programmable Logic Controller atau PLC.}

Programmable Logic Controller atau PLC adalah sebuah alat yang digunakan untuk menggantikan rangkaian sederetan relay yang ada pada sistem kontrol konvensional. PLC bekerja dengan cara mengamati masukan (melalui sensor), kemudian melakukan proses dan melakukan tindakan sesuai yang dibutuhkan, berupa menghidupkan atau mematikan keluaran. Program yang digunakan adalah berupa ladder diagram yang kemudian harus dijalankan oleh PLC. Dengan kata lain PLC menentukan aksi apa yang harus dilakukan pada instrument keluaran yang berkaitan dengan status suatu ukuran atau besaran yang diamati. Proses yang di kontrol ini dapat berupa regulasi variabel secara kontinyu seperti pada sistem - sistem servo, atau hanya melibatkan kontrol dua keadaan (on/off) saja, tetapi dilakukan secara berulang-ulang seperti umum dijumpai pada mesin pengeboran, sistem konveyor dan lain sebagainya. 
PLC secara bahasa berarti pengontrol logika yang dapat diprogram, tetapi pada kenyataannya, PLC secara fungsional tidak lagi terbatas pada fungsifungsi logika saja. Sebuah PLC dewasa ini juga dapat melakukan perhitunganperhitungan aritmatika yang relatif kompleks, fungsi komunikasi, dokumentasi dan lain sebagainya. PLC banyak digunakan pada aplikasi-aplikasi industri, misalnya pada proses pengepakan, perakitan otomatis dan lainlain. Hampir semua aplikasi kontrol listrik membutuhkan PLC. Alasan utama perancangan PLC adalah untuk menghilangkan beban ongkos perawatan dan penggantian sistem kontrol mesin berbasis relay. Adapun ciri atau karateristik PLC memiliki beberapa aspek sebagai berikut :

a. PLC sebenarnya suatu sistem berbasis mikroprosesor yang memiliki fungsi fungsi dan fasilitas utama dari sebuah mikro komputer.

b. PLC diprogram melalui programming unit yang bisa berupa terminal komputer dengan VDU (Video Display Unit) dan keyboard atau dengan terminal portabel khusus (mirip kalkulator dengan tampilan LCD). Pada saat ini PLC dapat di program melalui PC.

c. PLC mengontrol suatu alat berdasarkan status masukan/keluaran suatu alat dan program.

Sehingga pengertian PLC yang awalnya berfungsi menggantikan peran relay, dapat diartikan sesuai kata penyusunnya adalah sebagai berikut :

a. Programmable yaitu menunjukkan kemampuannya yang dapat dengan mudah diubah-ubah sesuai program yang dibuat dan kemampuannya dalam hal memori program yang telah dibuat.

b. Logic yaitu menunjukkan kemampuannya dalam memproses input secara aritmatik (ALU) dengan melakukan proses membandingkan, menjumlahkan, mengkalikan, membagi, dan mengurangi.

c. Controller yaitu menunjukkan kemampuannya dalam mengontrol

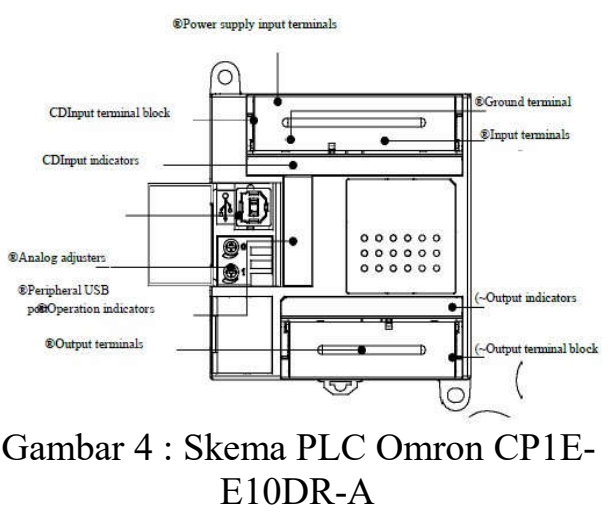

\section{c. Kamera Axis Q1614}

Kamera yang di gunakan adalah type IP kamera yang sering digunakan untuk CCTV yaitu kamera Axis Q1614. Fitur yang digunakan adalah berupa rekaman video yang diperintah melalui external input dari PLC berupa contact output PLC yang diterima kamera sebagai inputan melalui port I/O pada port 1 dan 3. Kemudian kamera akan menganalisa dan memberikan perintah untuk merekam kejadian yang ditangkap kamera dengan settingan system 3 detik sebelum terjadi contact dan 5 detik selama contact terjadi atau yang disebut dalam hal ini (pelanggaran), setelah perintah merekam ini selesai maka akan disimpan melalui penyimpanan SD card yang ada pada kamera. 


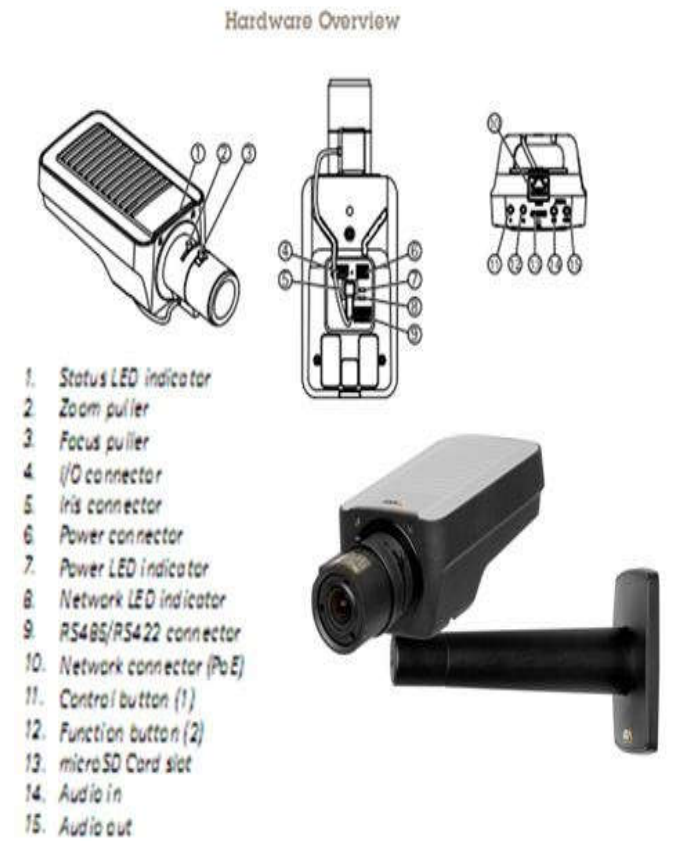

Gambar 5 Rangkaian Kamera Axis Q1614

\section{d. Battery BSB 12V 7,2Ah}

Power supply yang digunakan pada prototipe ini menggunakan battery BSB 12V 7,2Ah. Berikut spesifikasi dari battery BSB $12 \mathrm{~V} 7,2 \mathrm{Ah}$ :

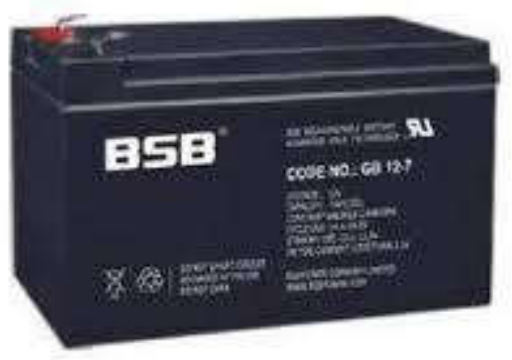

Gambar 6 Rangkaian Kamera Axis Q1614

d. Battery BSB $12 \mathrm{~V} 7,2 \mathrm{Ah}$

\section{METODE PENELITIAN}

\section{a. Kerangka Penelitian}

Metode pengerjaan dilakukan secara berurutan dengan langkah-langkah yang digunakan untuk membahas permasalahan yang diambil dalam penelitian. Adapun aturan pengerjaan skripsi ini digambarkan pada sebuah kerangka penelitian seperti pada gambar 3.1

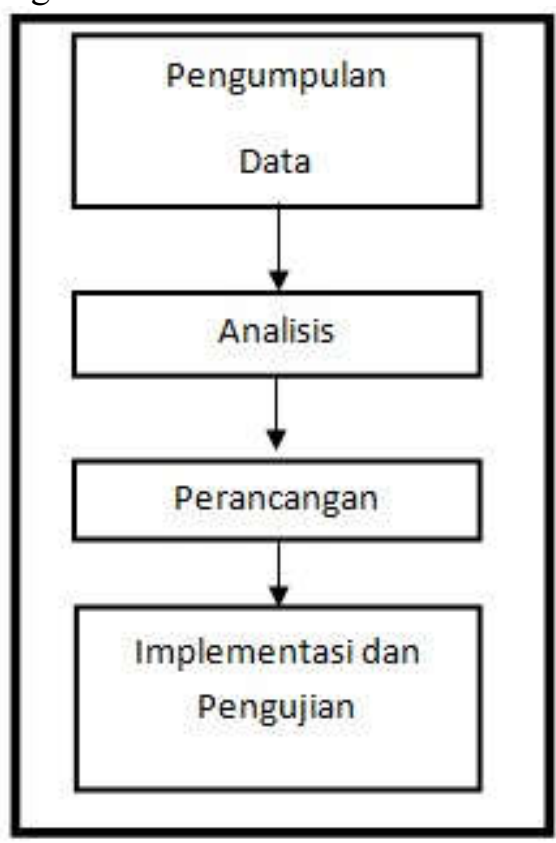

Gambar 7 Flowchart Kerangka Penelitian

\section{b. Pengumpulan Data}

Pengumpulan data merupakan proses pengadaan data primer untuk keperluan penelitian. Pengumpulan data merupakan langkah yang amat penting dalam metode ilmiah, karena pada umumnya data yang dikumpulkan digunakan untuk menguji hipotesis yang telah dirumuskan. Data yang dikumpulkan harus cukup valid untuk yang digunakan (Nazir,2005).

Adapun metode yang gunakan dalam pengumpulan data adalah sebagai berikut:

\section{Wawancara}


Wawancara adalah salah satu metode penelitian yang meliputi pengumpulan data melalui interaksi verbal secara lansung antara pewawancara dan responden (Sevilla, Et al, 1993).

Pada tahap ini wawancara yang dilakukan adalah proses tanya jawab dalam penelitian yang berlangsung secara lisan dengan pihak- pihak yang berkompeten. Wawancara dilakukan terhadap informasi yang telah ditentukan untuk mendapatkan informasi yang lebih jelas dan mendalam tentang berbagai hal yang diperlukan, yang berhubungan dengan masalah penelitian, juga untuk merespon berbagai pendapat untuk meningkatkan kinerja yang akan datang. Adapun yang menjadi narasumber untuk diwawancara yaitu dari pihak PT. Chevron Pacific Indonesia bagian IT / Telnet selaku badan yang mengawasi dan menangani area tempat peneliti melakukan penelitian dan Security sebagai petugas lalu lintas di area lingkungan PT. Chevron Pacific Indonesia.

\section{Pengamatan}

Pengamatan dalam istilah sederhana adalah proses dimana peneliti atau pengamat melihat situasi penelitian (Sevilla, Et al, 1993).

Pada tahap ini yang diamati adalah pertigaan jalan yang menjadi tempat peneliti melakukan penelitian, yaitu pada satu tempat pertigaan jalan yang ada di PT. Chevron Pacific Indonesia. Pada pertigaan jalan tersebut sudah ada tanda stop sign dan spanduk (banner) yang bergambarkan security sedang memegang tanda stop sign yang diletakkan tepat di depan pertigaan jalan. Spanduk (banner) berfungsi agar setiap pengendara yang melewati pertigaan jalan melihat bahwa dipertigaan jalan tersebut ada tanda stop dan mengharuskan pengendara berhenti sejenak sebelum melanjutkan perjalanan. Namun, spanduk (banner) tersebut tidak banyak membantu dan terlihat hanya sebagai gambar saja.

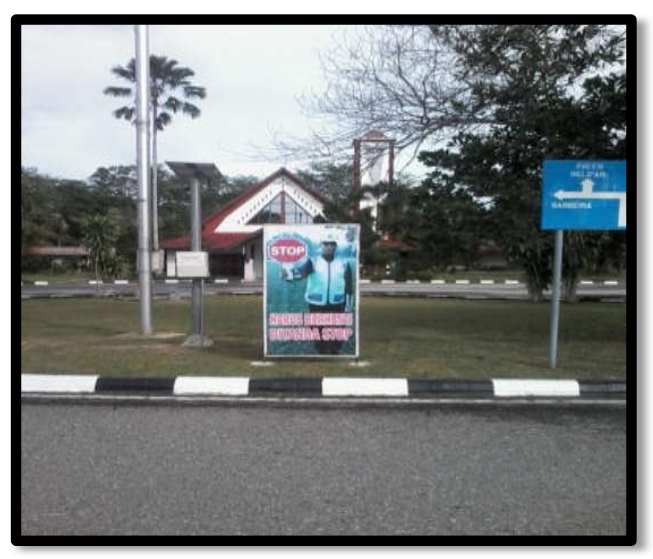

Gambar 8 Foto Spanduk / Banner Tanda Stop

\section{Studi Literatur}

$\begin{array}{lrr}\text { Studi } & \text { Literatur } & \text { meliputi } \\ \text { pengidentifikasian } & \text { secara } & \text { sistematis, } \\ \text { penemuan, dan } & \text { analisis } & \text { dokumen- }\end{array}$ dokumen yang informasi yang berkaitan dengan masalah penelitian (Sevilla, Et al, 1993).

Pada tahap studi literatur ini mengambil referensi - referensi dari berbagai sumber yaitu buku yang membahas tentang fungsi dan kegunaan Programmable Logic Controller (PLC), media internet, dan jurnal. Jurnal yang jadi acuan adalah jurnal-jurnal yang membahas masalah-masalah sensor photoelectric dan Programmable Logic Controller (PLC). Studi literatur tersebutlah yang menjadi pedoman untuk perancangan sistem yang di usulkan dalam pembuatan dan perancangan prototipe ini.

\section{c. Analisis}


Menganalisis kebutuhan dari sistem kerja prototipe alat yang akan dibuat. Serta menganalisis sistem prototipe alat yang sudah ada sebelumnya. Mendefinisikan kebutuhan-kebutuhan dari prototipe alat yang akan dirancang, mengumpulkan data, evaluasi data yang dilakukan dengan cara menetapkan data mana yang dipakai dan bila terjadi kekurangan data dapat dilakukan penambahan maupun perbaikan.

\section{d. Perancangan}

Pada tahap perancangan akan dilakukan rancangan perngkat lunak dan perangkat keras terhadap sistem yang akan dibuat. Alat bantu yang digunakan dalam perancangan adalah data flow diagram, blok diagram serta rangkaian fisik dari alat yang dibuat.

\section{e. Tahap Implementasi}

Tahap implementasi merupakan tahap penyusunan perangkat lunak sistem (coding), tahap perakitan perangkat keras, dan pengujian (testing) apakah sistem dapat berjalan sesuai kebutuhan. Untuk mengimplementasikan aplikasi ini maka dibutuhkan perangkat pendukung. Perangkat tersebut berupa perangkat keras dan perangkat lunak.

Adapun modul yang digunakan untuk pembuatan sistem adalah PLC Omron CP1E-E10DR-A yang telah terkombinasi menjadi hardware dengan bahasa pemrograman ladder, sensor photoelectric optex-fa VD-300 sebagai alat untuk mendeteksi kendaraan, kamera axis Q 1614 sebagai alat perekam untuk mengetahui pengendara yang melanggar rambu-rambu tanda stop, kabel serial sebagai perangkat tambahan untuk menghubungkan PLC dan kamera ke dalam perangkat komputer. Dan laptop thosiba L840D sebagai interface dari prototipe yang dibuat.

\section{f. Tahap Pengujian}

Pada tahap pengujian ini prototipe akan diujikan dalam bentuk simulasi, sedangkan tempat pengujian dilakukan pada suatu tempat dimana simulasi yang dibuat sedemikian rupa agar prototipe dapat memberitahu pengendara yang melanggar rambu-rambu tanda stop.

Simulasi yang dibuat berupa memasang 2 buah sensor pada simulator pertigaan jalan, dimana kendaraan yang datang dan berhenti pada garis stop akan terbaca oleh sensor 1. Bila kendaraan tersebut berhenti pada garis stop selama 3 detik, lalu baru melanjutkan perjalanan sensor 2 tidak akan merespon karena pengendara tidak melakukan pelanggaran. Sebaliknya, apabila pengendara tidak berhenti pada garis stop dan langsung melanjutkan perjalanan, maka setelah terbaca oleh sensor 1 kendaraan akan langsung terbaca oleh sensor 2 dan sistem akan membaca pengendara tersebut melakukan pelanggaran.

Selanjutnya kamera yang dipasang akan merekam secara otomatis ketika apabila ada pengendara yang melakukan pelanggaran. Untuk mendapatkan hasil yang optimal sensor 1 diletakkan pada rambu-rambu stop tepat pada garis berhenti kendaraan pada pertigaan jalan, sedangkan sensor 2 diletakkan disampingnya dengan jarak $20 \mathrm{~cm}$ pada simulator pertigaan jalan.

\section{HASIL DAN PEMBAHASAN}

\section{a. Analisis Sistem}

Sistem alat yang akan di buat berupa prototipe miniatur jalan pada suatu persimpangan pertigaan jalan. Sensor diletakkan disamping jalan atau trotoar 
persimpangan jalan dengan mengunakan dua sensor. Sensor \#1 diletakkan ditrotoar dibelakang garis stop sekitar $3 \mathrm{~cm}$ dan sensor \#2 diletakkan ditrotoar didepan garis stop sekitar $1 \mathrm{~cm}$ pada miniatur jalan. Sensor akan mengirimkan signal ke PLC sebagai controller yang telah diprogram untuk menentukan pengendara melanggar atau tidak dipersimpanganpetigaan jalan. PLC akan mengirimkan perintah ke kamera untuk merekam pelanggaran yang terjadi, sehingga pihak security dapat mempunyai data kongkrit tentang pelanggaran di persimpangan tersebut.

\section{b. Analisis Kebutuhan Fungsional}

Analisis kebutuhan ini merupakan aktivitas-aktivitas apa saja yang dapat dilakukan oleh prototipe alat yang akan dirancang, berikut ini kebutuhan fungsional yang diperlukan dalan perancangan prototipe alat.

1. Sensor photoelectric harus bisa membaca kendaraan yang melewati sensor dan memberi inputan ke controller.

2. PLC (Programe Logic Control) harus memastikan sensor sudah bekerja dengan benar sehingga dapat memproses semua aktivitas dari input yang diterima sesuai dengan program yang telah dibuat.

3. PLC (Programe Logic Control) dapat memberikan perintah ke kamera untuk merekam ketika terjadi pelanggaran.

4. Kamera harus bisa merekam pelanggaran ketika mendapatkan perintah Input dari PLC sebagai controller.

5. Micro SD harus bisa menyimpan file rekaman pelanggaran yang terjadi

\section{c.Analisis Kebutuhan Perangkat Lunak}

Kebutuhan perangkat lunak (software) merupakan kebutuhan bersifat program aplikasi yang digunakan untuk memprogram dan mengendalikan perangkat keras yang ada pada prototipe alat, agar semua alat dapat menjalankan tugas sesuai dengan perintah yang diberikan. Kebutuhan perangkat lunak yang dibutuhkan oleh sistem dapat dilihat pada tabel 4.1 :

Tabel 4.1 : Daftar Kebutuhan Perangkat Lunak (Soffware)

\begin{tabular}{|c|l|l|l|}
\hline No & \multicolumn{1}{|c|}{ Software } & Jenis Sofware & \multicolumn{1}{|c|}{ Kegunaan } \\
\hline 1 & Sistem Operasi & Windows 7 & $\begin{array}{l}\text { Sebagai sistem operasi yang akan } \\
\text { menjalankan sistem aplikasi yang } \\
\text { berjalan di atasnya. }\end{array}$ \\
\hline 2 & $\begin{array}{l}\text { Bahasa } \\
\text { pemrograman }\end{array}$ & $\begin{array}{l}\text { Ladder } \\
\text { diagram }\end{array}$ & $\begin{array}{l}\text { Bahasa pemrograman yang akan } \\
\text { di gunakan untuk mengisi } \\
\text { program perintah pada PLC. }\end{array}$ \\
\hline 3 & $\begin{array}{l}\text { Bahasa } \\
\text { pemrograman }\end{array}$ & PHP & $\begin{array}{l}\text { Bahasa pemrograman yang akan } \\
\text { di gunakan untuk menampilkan } \\
\text { file rekaman pelanggaran. }\end{array}$ \\
\hline 4 & $\begin{array}{l}\text { Aplikasi } \\
\text { Pemrograman }\end{array}$ & $\begin{array}{l}\text { Xampp } \\
\text { Pemrograman }\end{array}$ & $\begin{array}{l}\text { Software compiler khusus untuk } \\
\text { komunikasi ke web server. }\end{array}$ \\
\hline 6 & $\begin{array}{l}\text { Pengaturan } \\
\text { kamera }\end{array}$ & IP Utility & $\begin{array}{l}\text { Software compiler khusus untuk } \\
\text { memprogram PLC }\end{array}$ \\
\hline
\end{tabular}

\section{d. Analisis Kebutuhan Perangkat Keras} Sedangkan kebutuhan pangkat keras (hardware) merupakan kebutuhan berupa alat yang secara fisik dapat kita gabungkan dan berjalan sesuai dengan perintah yang telah diprogram oleh perangkat lunak. Jika diumpamakan seperti manusia perangkat lunak merupakan urutan pekerjaan yang harus dikerjakan oleh alat sesuai dengan fungsinya, sementara itu perangkat keras merupakan indera yang dapat bergerak, merasakan situasi lingkungan dan berjalan, seperti tangan kaki penglihatan dan pendengaran manusia. Sehingga semua perangkat keras dan perangkat lunak dapat bermanfaat untuk membantu banyak pekerjaan manusia sesuai yang diinginkan. Adapun kebutuhan perangkat 
keras yang digunakan untuk merancang prototipe alat ini dapat dilihat pada tabel 4.2.

\begin{tabular}{|c|c|c|}
\hline NO & Perangkat keras & Keterangan \\
\hline 1 & Laptop Thosiba L840D & $\begin{array}{l}\text { Untuk menjalank anperangkat } \\
\text { lunak, dan seluruh sumber daya } \\
\text { yang ada. }\end{array}$ \\
\hline 2 & PLC Omron CP1E-E10DR-A & $\begin{array}{l}\text { Otak pengendali perangkat keras } \\
\text { lain yang terhubung dengannya. }\end{array}$ \\
\hline 3 & Sensor Photoelectric & Sensor pendeteksikendaraan \\
\hline 4 & Kamera axis Q1614. & Alat perekam pelanggaran. \\
\hline 5 & Battery BSB & Power Supply. \\
\hline 6 & Kabel Serial $C S B$ & $\begin{array}{l}\text { Penghubung antara } P L C \text { dengan } \\
\text { laptop. }\end{array}$ \\
\hline 7 & Kabel petskot & $\begin{array}{l}\text { Penghubung antara kamera dengan } \\
\text { laptop. }\end{array}$ \\
\hline 8 & $\begin{array}{l}\text { Tang Potong, Kabel, Test Pen, } \\
\text { Multitester. }\end{array}$ & $\begin{array}{l}\text { Perangkat pendukung untuk } \\
\text { kebutuhan semua perangkat } \\
\text { elektronik. }\end{array}$ \\
\hline 9 & Miniatur Pertiga an Jalan & Media simulasi pertiga anjalan \\
\hline 0 & Mobil-mobilan & Sebagai simulasi kendaraan \\
\hline 11 & Box Panel & Tempat $P L C$ dan Battery \\
\hline 12 & Miniatur stop sign & Media simula si tanda berhenti \\
\hline
\end{tabular}

\section{PENUTUP}

\section{a. Kesimpulan}

Dari hasil perancangan dan Penerapan Sistem Stop Sign Pada Pertigaan Jalan Berbasis Sensor Photoelectric Pada PT. Chevron Pasific Indonesia serta hasil pembahasan yang telah diuraikan pada bab-bab sebelumnya, maka dapat ditarik kesimpulan sebagai berikut:

1. Sistem stop sign menggunakan modul PLC Omron CP1E-E10DR-A sebagai otak keseluruhan sistem untuk menentukan pembacaan sensor photoelectric Optex fa VD-300 apakah kendaraan melanggar atau tidak. Apabila sensor membaca pelanggaran maka PLC akan memerintahkan sistem mengaktifkan

2. kamera axis Q1614 untuk merekam pelanggaran yang terjadi.
3. Dari hasil pengujian sensor photoelectric Optex fa VD-300 dapat mendeteksi kendaraan yang berbelok kekiri maupun kekanan dengan baik.

4. Sistem membaca pengendara melakukan pelanggaran apabila tidak berhenti pada sensor 1 (dibelakang garis tanda stop) kurang dari 3 detik.

5. Hasil pengujian sensor menunjukkan bahwa sensor photoelectric Optex fa VD-300 dapat membaca setiap benda (padat), hewan dan manusia yang melintas di daerah pembacaan sensor.

6. Sistem merekam secara continue setiap ada pelanggaran dan menyimpan hasil rekaman kedalam sd card yang ada pada kamera axis Q1614.

7. Untuk mendapatkan view yang diinginkan yaitu pembacaan plat kendaraan, kamera axis Q1614 harus diletakkan tepat di depan pertigaan jalan.

8. Sistem stop sign dilengkapi dengan aplikasi rekapitulasi pelanggaran. Sehingga apabila ingin mengetahui berapa banyak pelanggaran yang terjadi dalam sehari, sebulan, maupun setahun dapat diketahui dengan mudah.

\section{b. Saran}

Untuk melanjutkan penelitian ini, peneliti mempunyai beberapa saran pengembangan penelitian yaitu:

1. Untuk mendapatkan pembacaan sensor yang akurat kita dapat mengganti sensor dengan sensor yang hanya mendeteksi kendaraan saja.

2. Pemindahan data rekaman dari kamera laptop masih dilakukan dengan manual. Diharapkan adanya suatu sistem yang dapat langsung mengambil data dari kamera sehingga secara otomatis dapat melakukan 
rekapitulasi file rekaman pelanggaran.

\section{DAFTAR PUSTAKA}

AASHTO. 2001. A Policy On Geometric Design of Hightways And Streets. Washington, D.C.

Achmad, K. dan Purnawarman, M. 2008. Robot Penghindar Objek Menggunakan Sensor Photoelectric. Penulisan Ilmiah. Fakultas Ilmu Komputer Universitas Gunadarma.

Agus, M. C. 2007. Perancangan Pengendalian Mesin Penyemprot Dan Pengering Cat Berbasis PLC. Unika Soegijapranata. Semarang

Bishop \& Owen. 2004. Dasar-dasar Elektronika. Erlangga : Jakarta.

Directorat Jendral Bina Marga \& Direktorat Bina Jalan Kota (BINKOT). 1997. Manual Kapasitas Jalan Indonesia (MKJI).

Djodi, A. 2012. Lampu Pengatur Rambu Lalu Lintas Portable dengan Menggunakan Kendali Logika Terprogram. Jurusan Teknik Elektro Politeknik Negeri. Semarang.

Hendri, A., Nandang, T., Decy N. 2013.Perancangan Simulator Sistem Pengepakan dan Penyortiran Barang berbasis PLC Twido TWDLMDA20DTK. Jurusan Teknik Elektro Institut Teknologi Nasional. Bandung.

Hendarto, S., L. dkk. 2001. Dasar Dasar Transportasi. ITB : Bandung.
Iwan, S. 2006. Programmable Logic Controller dan Teknik Perancangan Sistem Kontrol. Andi offset : Yogyakarta.

Malvino \& Albert, P. 1979. PrinsipPrinsipElektronika. Erlangga : Jakarta. Malvino \& Hanafi, G. 1999. Prinsip-Prinsip Electronika. Ed 2. Erlangga : Jakarta

Moh. Nazir. 2005, Metode Penelitian. Ghalia Indonesia : Bogor.

Omron. 2009. Instruction Reference Manual CP1E CPU Unit. Omron Corporation : Tokyo Japan.

Otto, M., A. 2008. Penggunaan Sensor Photoelectric Untuk Pengawasan Distribusi Alumina (Aplikasi PT. Inalum). Universitas Sumatra Utara.

Puslitbang Jalan dan Jembatan. 2007. Monitoring Teknologi Keselamatan Jalan. Laporan Akhir. Bandung.

Samuel, C., S., Budi, S., Erdhi, W. Perancangan Pengaturan Sistem Traffic Light Dengan CCTV Dinamis : Deteksi Kepadatan Jalan Denagn Citra Digital Pada Meket Jalan Simpang Empat. Teknik Elektro Universitas Katolik Soegijapranata. Semarang.

Sevilla, C. Et al. 1993. Pengantar Metode Penelitian. Universitas Indonesia Press 